\title{
Indicadores Educacionais sobre a Educação Especial no Brasil e no Paraná
}

\author{
Silvia Márcia Ferreira Meletti' \\ 'Universidade Estadual de Londrina (UEL), Londrina/PR - Brasil
}

RESUMO - Indicadores Educacionais sobre a Educação Especial no Brasil e no Paraná. O objetivo do trabalho é analisar a escolarização de alunos com necessidades educacionais especiais por meio dos dados oficiais do poder público sobre o acesso e permanência desta população na Educação Básica. Para tanto, são utilizados microdados do Censo da Educação Básica brasileira e do Paraná no ano de 2012. As análises apontam, a despeito da implantação da política de educação inclusiva, que: formas de atendimento segregado ainda estão marcadamente presentes no Paraná; a concentração de matrículas ocorre nas primeiras séries do ensino fundamental, com ampla defasagem idade/série e o baixo número de matrículas no atendimento educacional especializado.

Palavras-chave: Educação Inclusiva. Política Educacional. Educação Especial. Indicadores Educacionais.

ABSTRACT - Educational Indicators of Special Education in Brazil and in the State of Paraná. The objective of the work is to analyze the schooling of students with special educational needs by means of governmental official data about the access and permanence of this population in the K-12 education. Thus, microdata from the Brazilian Basic Education Census and from Paraná (2012) are used. The analysis shows that, in spite of the implementation of the inclusive education policy, modes of segregated service still are strongly present in Paraná, enrollment concentrates around the initial grades of the K-12 education, with wide age/grade discrepancy, and a low number of enrollments for specialized educational services.

Keywords: Inclusive Education. Educational Policy. Special Education. Educational Indicators.

Educação \& Realidade, Porto Alegre, v. 39, n. 3, p. 789-809, jul./set. 2014.

Disponível em: <http://www.ufrgs.br/edu_realidade> 
Indicadores Educacionais sobre a Educação Especial no Brasil e no Paraná

\section{Introdução}

O presente trabalho tem por objetivo analisar a configuração da educação especial no estado do Paraná. Para tanto, analisamos a política de educação especial vigente no estado que regulamenta a escolarização de pessoas com necessidades educacionais especiais e os dados oficiais do poder público acerca desta população. Tomamos como unidade de análise a incidência demográfica e os eventos educacionais sobre o acesso e as condições de permanência na educação básica dessa população, tendo como fonte as estatísticas públicas do Censo da Educação Básica de 2012, coletadas e divulgadas pelo Instituto Nacional de Estudos e Pesquisas Educacionais Anísio Teixeira (INEP). O ano selecionado apresenta os dados de matrícula posteriores à transformação das instituições especiais em Escolas da Educação Básica, na modalidade de Educação Especial, e se refere ao último disponibilizado pelo INEP até o momento de finalização deste texto.

A opção por analisar as estatísticas públicas se justifica pelo fato de serem informações oficialmente utilizadas,

$$
\begin{aligned}
& \text { [...] para traçar um panorama nacional da educação básica e } \\
& \text { servem de referência para a formulação de políticas públicas } \\
& \text { e execução de programas na área da educação, incluindo os } \\
& \text { de transferência de recursos públicos como merenda e trans- } \\
& \text { porte escolar, distribuição de livros e uniformes, implanta- } \\
& \text { ção de bibliotecas, instalação de energia elétrica, Dinheiro } \\
& \text { Direto na Escola e Fundo de Manutenção e Desenvolvimen- } \\
& \text { to da Educação Básica e de Valorização dos Profissionais da } \\
& \text { Educação (Fundeb) (Brasil, 201la, online). }
\end{aligned}
$$

O Censo da Educação Básica é um levantamento anual de dados estatístico-educacionais de âmbito nacional, coordenado pelo INEP. A coleta é feita em todas as escolas públicas e privadas do país, responsáveis pelo preenchimento de um formulário disponível no sistema on-line Educacenso. Trata-se do principal instrumento de coleta de informações da educação básica, que abrange as suas diferentes etapas e modalidades coletando dados sobre estabelecimentos, matrículas, funções docentes, movimento e rendimento escolar. Os dados são parcialmente divulgados pelo INEP por meio das Sinopses Estatísticas da Educação Básica.

Além da divulgação parcial dos dados, o INEP disponibiliza os bancos de microdados sobre as escolas, as matrículas, as turmas e docentes. Nestes bancos de microdados é possível acessar as informações sobre todas as unidades escolares, todos os alunos, todas as turmas e todos os docentes da Educação Básica Brasileira. Para acessar os microdados é necessário a utilização de softwares estatísticos. No presente trabalho utilizamos o software IBM SPSS Statistics (Statistical Package for the Social Science) para extração e organização dos dados.

Em todo o universo de dados disponíveis nos bancos de microdados do INEP, selecionamos e organizamos aqueles referentes à ma- 
trícula de alunos com necessidades educacionais especiais, no estado do Paraná. Os dados sobre essa população registram as matrículas de alunos com deficiência (física, intelectual, visual e auditiva), transtorno global do desenvolvimento (autismo infantil, Síndrome de Asperger, Síndrome de Rett, transtorno desintegrativo da infância) e altas habilidades/superdotação (Brasil/MEC/INEP, 2012a).

Para a análise do acesso à educação trabalhamos com duas estatísticas públicas, uma referente aos dados demográficos sobre incidência da população com algum tipo de deficiência, segundo frequência à escola no Brasil e no Paraná (Brasil/IBGE, 2010a, e outra referente às matrículas na educação básica (Brasil/MEC/INEP, 2012a).

As informações demográficas sobre pessoas com deficiência foram coletadas por amostragem. Foi investigada a existência de deficiência visual, auditiva, física (denominada no Censo Demográfico como motora) e a deficiência mental/intelectual (segundo denominação do Censo Demográfico). Durante a coleta dos dados a pergunta realizada era se havia alguma pessoa na residência com dificuldade permanente para enxergar, ouvir, caminhar ou subir degraus. Quanto à deficiência mental/intelectual, perguntava-se se havia alguma pessoa com deficiência mental/intelectual permanente que limite suas atividades habituais como trabalhar, ir à escola, brincar etc. As respostas foram dadas selecionando uma das seguintes categorias: não consegue de modo algum, com grande dificuldade, com alguma dificuldade e nenhuma dificuldade. Para a deficiência mental/intelectual apenas sim ou não. Além disso, o Censo Demográfico apresenta as características desta população segundo faixa etária e frequência à escola (Brasil/IBGE, 2010a).

Contudo, os dados demográficos também apresentam limites, haja vista a grande possibilidade, por exemplo, de pessoas com problemas visuais que, mesmo sem se enquadrarem na condição de deficiência visual, terem se declarado como tais. O mesmo ocorre com os outros tipos de deficiência.

Em função da amplitude das categorias do Censo Demográfico, no presente trabalho utilizamos para nossas análises os dados referentes à categoria não consegue de modo algum para as deficiências visual, auditiva e motora. Também consideramos os dados referentes à deficiência mental/intelectual.

Outra delimitação feita foi em relação à faixa etária das pessoas declaradas como com deficiência: trabalhamos com os dados referentes à faixa etária entre 0 e 19 anos, o que permitiu analisar a incidência de deficiência na população em idade escolar.

Selecionamos e organizamos os dados demográficos de 2010 no banco de dados agregado, a partir do Sistema IBGE de Recuperação Automática - SIDRA (Brasil/IBGE, 2010a).

Com relação às matrículas, tomamos os dados de alunos com necessidades educacionais especiais verificando sua incidência em re- 
Indicadores Educacionais sobre a Educação Especial no Brasil e no Paraná

lação aos dados gerais da Educação Básica. Agregamos os dados por: (1) Modalidade de Ensino - ensino regular com as matrículas em classes regulares e em salas de recurso multifuncionais e ensino especial com as matrículas em instituições e classes especiais (modalidade substitutiva de ensino); (2) Dependência Administrativa da Escola - pública ou privada.

As condições de permanência dessa população na Educação Básica paranaense foram analisadas a partir da distribuição das matrículas segundo Modalidade de Ensino e Etapas de Ensino (Creche, Pré-escola, Ensino Fundamental, Ensino Médio e Educação de Jovens e Adultos (EJA)), Atendimento Educacional Especializado e do cotejamento dos dados sobre a relação Idade-Série.

Além disso, utilizamos os dados gerais da Educação Básica brasileira e os dados do Censo Demográfico do IBGE de 2010 sobre incidência da população com algum tipo de deficiência no Brasil. Isso permitiu dimensionar a realidade do estado do Paraná.

Para contemplarmos as análises propostas, inicialmente apresentamos e analisamos a política de educação especial no Brasil e o modo como foi apropriada no estado do Paraná. Trabalhamos com as proposições legais e normativas do período entre 1996 e 2011, no caso nacional, e do período de 2011 a 2012, no caso estadual. O primeiro período foi selecionado em função da ênfase na perspectiva inclusiva presente nos documentos e, o segundo, relativo à política educacional implementada no Paraná como decorrência da regulamentação do Atendimento Educacional Especializado, conforme os Decretos 6.571 de 2008 e 7.611 de 2011 (que revoga o anterior).

Na sequência, tratamos das estatísticas públicas demográficas e educacionais referentes à pessoa com necessidade educacional especial, conforme descrito anteriormente. Delimitamos os eventos educacionais representativos do que consideramos condição para o processo de escolarização: o acesso à escola e as condições de permanência.

\section{Política de Educação Especial na Perspectiva Inclusiva}

No Brasil, a escolarização de pessoas com necessidades educacionais especiais constituiu-se por meio de serviços paralelos à educação regular, implementados, prioritariamente, em espaços segregados de ensino. Desse modo, esta população, quando atendida, o é em instituições especiais privadas de caráter filantrópico e em classes especiais, implementadas majoritariamente no sistema público de ensino. Como consequência, de acordo com Kassar e Meletti (2012, p. 50), “[...] o setor público atendeu de forma compartilhada, em sua maioria, alunos com deficiências mais leves em classes especiais em escolas públicas e o setor privado atendeu alunos com deficiências mais severas em instituições especializadas”. 
Segundo Ferreira e Ferreira, essa divisão de responsabilidades "[...] gerou um segmento social e econômico organizado em torno de escolas particulares, filantrópicas e/ou organizações não governamentais que envolvem muitos interesses, num peculiar processo de privatização" (Ferreira; Ferreira, 2004, p. 24).

O impacto dessa relação pode ser identificado nos dados estatísticos oficiais do final da década de 1980. Em 1988, o Ministério da Educação mostrava que, dos alunos que recebiam atendimento especializado no Brasil, 21,78\% estavam em instituições sob administração pública e 78,21\% em instituições privadas filantrópicas (Brasil, 1991a). A relação é diferente quando se considera a matrícula de alunos no ensino regular (para alunos de 7 a 14 anos): 2,82\% estavam matriculados em escolas privadas e 97,18\% estavam em escolas públicas (Brasil, 1991b). Para Jannuzzi (1997), a relação entre os setores público e privado, no que se refere à educação especial, chegou a se caracterizar como uma parcial simbiose, permitindo, de um lado, ao setor privado influenciar na determinação das políticas públicas brasileiras e, de outro, ao Estado estruturar a Educação Especial por meio da filantropia.

A partir da década de 1990, essa relação é afetada pela adesão, por parte do Brasil, às orientações internacionais tratadas na Declaração de Educação para Todos (Conferência Mundial de Educação para Todos, 1990) e na Declaração de Salamanca e linha de ação sobre necessidades educativas especiais (1994), resultado da Conferência Mundial sobre Necessidades Educacionais Especiais. Esses e outros documentos internacionais forneceram a base para a formulação das políticas educacionais brasileiras que incorporaram os discursos da universalização do ensino e da educação inclusiva. Cumpre destacar que, neste panorama,

\begin{abstract}
[...] ao assumir sua adesão à Declaração de Salamanca, o Brasil o faz numa perspectiva de compromisso internacional junto à Organização das Nações Unidas (ONU)/Organização das Nações Unidas para a Educação, a Ciência e a Cultura (UNESCO) e ao Banco Mundial (BM), que promoveram o encontro. Esses compromissos apontam mais para a necessidade de se melhorar os indicadores nacionais da educação básica, priorizando os aspectos quantitativos do acesso (Ferreira; Ferreira, 2004, p. 24).
\end{abstract}

No caso de alunos com necessidades educacionais especiais, o acesso à educação e a permanência na escola, preferencialmente na rede regular de ensino, estão garantidos na Constituição da República Federativa do Brasil de 1988 e na Lei de Diretrizes e Bases da Educação Nacional, Lei n. 9.394/96, assim como a exigência de adequação dos sistemas de ensino para atender as especificidades deste alunado.

Em 2001, a Resolução n. 2/2001 do Conselho Nacional de Educação (CNE), que instituiu as Diretrizes Básicas da Educação Especial, determina que "[...] os sistemas de ensino devem matricular todos os alunos, cabendo às escolas organizarem-se para o atendimento aos

Educação \& Realidade, Porto Alegre, v. 39, n. 3, p. 789-809, jul./set. 2014.

Disponível em: <http://www.ufrgs.br/edu_realidade> 
Indicadores Educacionais sobre a Educação Especial no Brasil e no Paraná

educandos com necessidades educacionais especiais, assegurando as condições necessárias para uma educação de qualidade para todos" (Brasil/CNE, 2001).

Por outro lado, esse mesmo aparato legal e normativo mantém a valorização da iniciativa privada por meio do apoio técnico e financeiro do Poder Público às instituiçõos especiais filantrópicas que atuem exclusivamente em educação especial e que atendam aos critérios estabelecidos pelos órgãos normativos dos sistemas de ensino, possibilitando seu reconhecimento como escola pertencente ao sistema comum de ensino (Brasil, 1996; Brasil, 2001). Assim, as instituições especiais filantrópicas são absorvidas como parte do sistema de serviços de educação especial na perspectiva inclusiva, para aqueles sujeitos em idade escolar obrigatória e também para todos os outros mediante novos processos de gestão (Garcia, 2013 p. 108).

Meletti e Bueno (2011) analisaram as alterações quantitativas referentes ao acesso de alunos com deficiência no sistema educacional brasileiro, no período de 1998 a 2006, e constataram um aumento de $48,14 \%$ no total de matrículas. Entretanto, os autores apontam que,

[...] se cotejarmos esse crescimento em relação ao número total de matrículas na escola básica nesse período, constataremos que, em 1998, as matrículas em educação especial (337.326) representaram $0,76 \%$ das matrículas totais (43,9 milhões) e que, em 2006, as matrículas em educação especial (700.624) representam 1,25\% das matrículas totais (55,9 milhões). Ou seja, em oito anos, o aumento percentual da educação especial em relação às matrículas totais foi de apenas $0,49 \%$. Se aceitarmos a estimativa da OMS, que calcula em $10 \%$ da população o número de pessoas com algum tipo de deficiência, e se esse crescimento for constante, levaremos 16 anos para acréscimo de $1 \%$ da demanda, o que redundaria em mais de 100 anos para chegarmos à matrícula de todos os alunos com deficiência na educação básica (Meletti; Bueno, 2011, p. 376).

Além disso, mostram que,

[...] houve um aumento significativo das matrículas em escola especial, muito superior à queda da primeira: crescimento de 56.353 matrículas em escolas especiais, de 1998 a 2006, contra uma diminuição de 9.191 em classes especiais, no mesmo período. O aumento significativo das matrículas em classes regulares é evidente: de 43.923 em 1998 para 325.136, em 2006, mas, apesar deste elevado crescimento, continuou inferior às matrículas dos sistemas segregados, que somaram 375.488 matrículas (Meletti; Bueno, 2011, p. 376).

Com a ampliação do acesso de alunos com necessidades educacionais especiais no sistema regular de ensino, os documentos legais e normativos da educação especial brasileira passam a enfatizar o modo como a escolarização dessa população deveria ser implementada. 
Em 2006, o Ministério da Educação publica o primeiro documento que definia o atendimento educacional especializado (AEE), a ser implementado em Salas de Recursos Multifuncionais, como:

[...] uma ação do sistema de ensino no sentido de acolher a diversidade ao longo do processo educativo, constituindo-se num serviço disponibilizado pela escola para oferecer o suporte necessário às necessidades educacionais especiais dos alunos, favorecendo seu acesso ao conhecimento (Brasil, 2006, online).

Em 2008 foi aprovado o Decreto n. 6.571/2008, que dispõe sobre o atendimento educacional especializado. Para a implementação deste Decreto, a Resolução CNE/CEB n. 4/2009 instituiu as Diretrizes Operacionais para o Atendimento Educacional Especializado na Educação Básica, modalidade Educação Especial, que, em seu artigo $5^{\circ}$, define:

O AEE é realizado, prioritariamente, na sala de recursos multifuncionais da própria escola ou em outra escola de ensino regular, no turno inverso da escolarização, não sendo substitutivo às classes comuns, podendo ser realizado, também, em centro de Atendimento Educacional Especializado da rede pública ou de instituições comunitárias, confessionais ou filantrópicas sem fins lucrativos, conveniadas com a Secretaria de Educação ou órgão equivalente dos Estados, Distrito Federal ou dos Municípios (Brasil, 2009a, online).

Vale destacar a centralidade do AEE, implementado nas salas de recursos multifuncionais, na atual política de educação especial brasileira. O que indica o modo como a escolarização de alunos com necessidades educacionais especiais será organizada: em escolas regulares públicas, nas classes comuns com o AEE ocorrendo no contraturno.

Contudo, Garcia (2013, p. 109) analisa que,

[...] em grande medida os modi operandi das salas de recursos, do ponto de vista do trabalho docente ali realizado, se mantêm como paralelo ao trabalho realizado na classe comum, o qual pouco incide sobre o processo de escolarização dos sujeitos da modalidade educação especial.

Em 2011, com a revogação do Decreto 6.571 de 2008 e com a aprovação do Decreto 7.611 de 2011, que dispõe sobre a educação especial e o atendimento educacional especializado, a dupla matrícula para alunos com necessidades educacionais especiais passa a ser admitida no caso daqueles que frequentam a rede regular e pública de ensino e que recebem o AEE oferecido "[...] pelos sistemas públicos de ensino ou por instituições comunitárias, confessionais ou filantrópicas sem fins lucrativos, com atuação exclusiva na educação especial, conveniadas com o Poder Executivo competente" (Art. $4^{\circ}$ e Art. $5^{\circ}$ ).

Educação \& Realidade, Porto Alegre, v. 39, n. 3, p. 789-809, jul./set. 2014.

Disponível em: <http://www.ufrgs.br/edu_realidade> 
Indicadores Educacionais sobre a Educação Especial no Brasil e no Paraná

É necessário destacar que esta configuração da política pública para a educação de pessoas com necessidades educacionais especiais, numa perspectiva inclusiva, não é acatada e efetivada do mesmo modo nas diferentes unidades federadas do Brasil. De acordo com Kassar e Meletti (2012, p. 54),

[...] como qualquer política pública, a política educacional não é efetivada sob uma relação unidirecional, em que leis são assimiladas 'automaticamente' e homogeneamente por todo país. [...] Nas diferentes localidades, as propostas sofrem interpretações, são lidas e entendidas diferentemente, de acordo com inúmeras variáveis históricas, econômicas e sociais.

No Paraná, a proposição legal e normativa do AEE não foi acatada. Isso porque, neste estado, a educação especial consolidou-se em instituições especiais filantrópicas. Em 2011, de acordo com dados divulgados pelo governo paranaense, o estado contava com 394 instituições especiais conveniadas com a Secretaria de Estado de Educação, distribuídas em um universo de 399 municípios.

Em agosto de 2011, após processo desencadeado pelo então governador Roberto Requião no início de 2010, é publicada a Resolução 3600/2011 (Paraná/GS/SEED, 2011) que, em seu artigo $1^{\circ}$, autoriza a

[...] alteração na denominação das Escolas de Educação Especial para Escolas de Educação Básica, na modalidade de Educação Especial, com oferta de Educação Infantil, Ensino Fundamental - anos iniciais, Educação de Jovens e Adultos - Fase I, e Educação Profissional/Formação inicial, a partir do início do ano letivo de 2011 (Paraná/GS/ SEED, 2011, s. p.).

Em seu artigo 2o, autoriza a participação das instituições em todos os programas e políticas públicas da área da educação, o que garante a manutenção dos subsídios públicos para o setor privado e dos alunos com necessidades educacionais especiais em espaços segregados de ensino.

Em agosto de 2013, é sancionada a Lei 17656/2013, que institui o programa estadual de apoio permanente às entidades mantenedoras de escolas que ofertam Educação Básica na modalidade Educação Especial, denominado Todos Iguais pela Educação.

Segundo a referida Lei, o estado do Paraná garantirá aos alunos com necessidades educacionais especiais, mediante instrumento administrativo legal adequado, o acesso igualitário aos benefícios dos programas educacionais suplementares disponíveis para o respectivo nível de ensino, incluindo os programas de alimentação e transporte escolar, construção, ampliação e reforma das unidades escolares, suprimento de mobiliários, equipamentos e materiais e capacitação. Além disso, designará professores, pedagogos e agentes educacionais para prestarem serviços "[...] nos programas educacionais ofertados pela Entidade 
Mantenedora, em conformidade com o número de alunos matriculados na escola" (Paraná, 2013 s. p.).

Cumpre analisar que, de acordo com a Constituição Federal de 1988, a República Federativa do Brasil compreende a União, os Estados, o Distrito Federal e os Municípios, todos autônomos. Saviani (2010) destaca que no campo educacional essa autonomia não pode permitir aos Estados se sobreporem aos dispositivos constitucionais regulamentados pela Lei de Diretrizes e Bases da Educação (LDB). Segundo o autor,

[...] dada uma federação como a brasileira, com seu arcabouço jurídico encabeçado não por acaso pela Constituição Federal, a forma plena de organização do campo educacional é traduzida pelo Sistema Nacional de Educação. Sua construção flui dos dispositivos constitucionais regulamentados pela Lei de Diretrizes e Bases da Educação Nacional (LDB), que é prerrogativa exclusiva da União e se especifica na legislação complementar. Constitui-se, desse modo, um sistema de educação pleno, obviamente público, inteiramente autônomo, com normas próprias que obrigam todos os seus integrantes em todo o território nacional. No âmbito dos estados, preserva-se um grau próprio de autonomia que lhes permite baixar normas de funcionamento do ensino, mas sem a plenitude de que goza a União, uma vez que devem subordinar-se às diretrizes e bases traçadas por ela, esfera que escapa à sua atribuição (Saviani, 2010, p. 383).

Outro aspecto a ser destacado sobre a política de educação especial do Paraná é a centralidade da iniciativa privada de caráter filantrópico na educação de pessoas com necessidades educacionais. Saviani (2010) analisa que,

As instituições privadas, em suas diferentes modalidades, integrarão o sistema precisamente como particulares, e é nessa condição que darão sua contribuição específica para o desenvolvimento da educação brasileira. Deve-se entender que, quanto mais autenticamente particulares elas forem, melhor se tipifica sua contribuição própria. Portanto, não cabe travesti-las de públicas, seja pela transferência de recursos na forma de subsídios e isenções, seja pela transferência de poder, admitindo-as na gestão e operação do complexo das instituições públicas que integram o sistema (Saviani, 2010, p. 385).

Ao instituir o programa Todos iguais pela educação, o governo do Paraná consolida a hegemonia das instituições especiais filantrópicas. Segundo o governador Beto Richa, que sancionou a Lei 17656/2013, o processo desencadeado em 2011 se tornou uma política pública, “[...] isso quer dizer que as escolas de Educação Especial não ficarão mais dependentes da vontade dos governantes para terem o apoio do governo". Enaltece, ainda, que a iniciativa é pioneira no país e que, "É fundamental que todos, diferentes nas suas necessidades, sejam iguais no direito

Educação \& Realidade, Porto Alegre, v. 39, n. 3, p. 789-809, jul./set. 2014 797

Disponível em: <http://www.ufrgs.br/edu_realidade> 
Indicadores Educacionais sobre a Educação Especial no Brasil e no Paraná

à educação de qualidade para desenvolver plenamente o seu potencial. Agora, isso é lei no Paraná” (Apoio..., 2013, online).

A declaração omite que o programa formaliza o modo como o poder público paranaense historicamente estruturou a educação especial no estado: segregado, privado e filantrópico. Assim, na contramão do que está determinado no Decreto 7611/2011, o estado do Paraná admite a permanência de alunos com necessidades educacionais exclusivamente em instituições especiais, sem a obrigatoriedade da matrícula em escolas regulares. Mais do que isso, legitima a incorporação dessas instituições no sistema de ensino que se estrutura, nacionalmente, em uma perspectiva inclusiva.

\section{Estatísticas Públicas sobre Pessoas com Necessidades Educacionais Especiais}

A análise dos documentos legais e normativos (Brasil, 1996; 2001; 2006; 2008b; 2011b), exposta anteriormente, nos permitiu delimitar indicadores que possibilitaram analisar a implementação da política de educação especial do estado do Paraná e seu impacto no processo de escolarização de pessoas com necessidades educacionais especiais. Tais indicadores se referem ao acesso e às condições de permanência desta população na escola.

\section{Acesso à Escola}

Entendemos que a política de educação especial em uma perspectiva inclusiva deve favorecer a ruptura com duas marcas da educação de pessoas com necessidades educacionais especiais no Brasil: o não acesso a nenhum tipo de escolarização, seja ele regular ou segregado, e a centralidade do sistema segregado de ensino consolidado em instituições especiais privadas de caráter filantrópico. Significa dizer que deve haver a ampliação do acesso à escola e a migração dessa população dos sistemas segregados para os sistemas regulares de ensino; assim como a ampliação da educação desta população nas escolas regulares públicas e diminuição nas escolas privadas, especialmente as de caráter filantrópico.

Para o desenvolvimento da análise sobre o acesso à escola, recorremos aos dados demográficos em função dos limites encontrados nos indicadores educacionais. Nos censos escolares a contagem dos alunos é feita a partir das matrículas, ou seja, por meio apenas dessa estatística pública não conseguiríamos analisar qual a incidência de pessoas com necessidades educacionais especiais que não frequentam a escola. Já para as análises da distribuição das matrículas segundo modalidade regular ou especial de ensino e dependência administrativa da escola, utilizamos os dados sobre os alunos com necessidades educacionais especiais do Censo da Educação Básica de 2012. 
De acordo com os dados demográficos de 2010, a população brasileira era de 190.755.799 pessoas. Destas, 45.606 .048 (23,91\%) se declararam com pelo menos uma das deficiências investigadas, $1.585 .004(0,84 \%)$ declararam que não conseguem de modo algum enxergar, ouvir, caminhar ou subir degraus e 2.611 .536 (1,36\%) afirmaram possuir deficiência mental/intelectual permanente que limite suas atividades habituais. No mesmo ano, a população paranaense era de 10.444 .526 pessoas. A incidência (em relação à população total do estado) da declaração de: com pelo menos uma das deficiências investigadas era de 2.280 .548 (21,83\%); não consegue de modo algum era de 85.094 (0,81\%); deficiência mental/ intelectual permanente era de 143.376 (1,37\%).

Observa-se que a incidência de pessoas com deficiência, nas categorias selecionadas, no Paraná, é equivalente à nacional. O cotejamento dos dados demográficos estaduais com os nacionais mostra que 5,47\% da população nacional vive no Paraná, assim como 5\% da população com pelo menos uma das deficiências, $5,36 \%$ daqueles que declararam não conseguir de modo algum enxergar, ouvir, caminhar ou subir degraus e 5,49\% dos que afirmaram possuir deficiência mental/intelectual permanente.

Para o dimensionamento do acesso de pessoas com deficiência à escola, selecionamos e organizamos os dados demográficos nacionais e do estado do Paraná de 2010 por faixa etária de 0 a 19 anos, tipo de deficiência (de modo algum e com deficiência mental/intelectual permanente) e frequência à escola.

Os dados do Censo Demográfico de 2010 mostram que, no Brasil, dos 190.755 .799 de pessoas, 59.565 .188 (31,23\%) frequentavam a escola em todos os níveis e etapas de ensino (educação básica e ensino superior) e $131.190 .611(68,77 \%)$ não frequentavam. A população brasileira com idade de 0 a 19 anos era de 62.928.423, dos quais 47.068.141 frequentavam a escola e 15.860.283 não frequentavam. Significa que $25,2 \%$ da população brasileira, em idade de 0 a 19 anos, não frequentava a escola em 2010. A maior incidência de frequência estava na faixa etária entre 5 e 14 anos, com $65,42 \%$ dos casos declarados. Contudo, nesta mesma faixa etária (5 a 14 anos), 1.338.322 pessoas não frequentavam a escola.

No Paraná, dos 10.444.526 de pessoas, 3.105 .958 (29,74\%) frequentavam a escola em todos seus níveis e etapas e 7.338 .568 (70,26\%) não frequentavam. A população estadual com idade entre 0 a 19 anos, em 2010, era de 3.319 .367 pessoas, das quais $2.463 .480(74,21 \%)$ frequentavam a escola e 855.886 (25,79\%) não frequentavam. Assim como os dados nacionais indicam, a maior incidência de frequência estava na faixa etária de 5 a 14 anos, com 65,57\% dos casos. Na mesma faixa etária, 62.012 pessoas não frequentavam a escola no estado.

No Brasil, dos 1.585.004 de pessoas que se declararam não consegue de modo algum, $1.319 .542(83,25 \%)$ não frequentavam a escola. Na faixa etária entre 0 e 19 anos, tínhamos 171.230 (54,45\%) frequentavam a escola e 143.199 (45,55\%) que não frequentavam. No caso das 
Indicadores Educacionais sobre a Educação Especial no Brasil e no Paraná

2.611.536 pessoas que se declararam com deficiência mental/intelectual permanente, 577.557 (22,11\%) tinham entre 0 e 19 anos. Destas, 365.465 $(63,27 \%)$ frequentavam a escola e 212.091 (36,73\%) não frequentavam.

No Paraná, das 85.094 pessoas que se declararam não consegue de modo algum, $70.710(83,1 \%)$ não frequentavam a escola. Na faixa etária de 0 a 19 anos, $9.826(58,58 \%)$ frequentavam a escola e 6.947 (41,42\%) não frequentavam. Das 143.376 pessoas com deficiência mental/intelectual permanente, 30.281 (21,11\%) frequentavam a escola e $113.095(78,89 \%)$ não frequentavam. Destas, 29.849 tinham de 0 a 19 anos, sendo que 20.693 $(69,32 \%)$ frequentavam a escola e 9.155 (30,68\%) não frequentavam.

Os dados do Censo Demográfico de 2010 mostram que o alcance das proposições políticas para a educação brasileira é limitado. Mesmo priorizando os aspectos quantitativos de acesso à escola para consolidar a universalização do ensino e a educação inclusiva, conforme indicaram Ferreira e Ferreira (2004), ainda encontramos um número expressivo (mais de quinze milhões) de pessoas em idade entre 0 e 19 anos fora da escola. No caso da pessoa com necessidade educacional especial essa situação se agrava, fundamentalmente para aqueles que se declararam não conseguir de modo algum ou possuírem deficiência mental/intelectual permanente.

Os dados apresentados sustentam a análise de que o acesso à escola de pessoas com deficiência ainda é precário, tanto no Brasil quanto no Paraná. Cumpre resgatar que a faixa etária selecionada compreende os períodos de escolarização obrigatória e também aqueles indicados como fundamentais, mas não obrigatórios: a educação infantil e o ensino médio.

Com relação ao modo como as matrículas de alunos com necessidades educacionais especiais estão distribuídas, segundo modalidade de ensino e dependência administrativa da escola, no Brasil e no Paraná, selecionamos e organizamos os dados do ano de 2012, conforme apresentado na Tabela 1 .

Tabela 1 - Número de alunos com NEE, no Brasil e no estado do Paraná, por dependência administrativa da escola - 2012

\begin{tabular}{c|c|c|c|c}
\hline \multirow{2}{*}{$\begin{array}{c}\text { Dependência } \\
\text { administrativa }\end{array}$} & \multicolumn{2}{c|}{ Ensino Regular } & \multicolumn{2}{c}{ Ensino Especial } \\
\cline { 2 - 5 } & Brasil & Paraná & Brasil & Paraná \\
\hline Pública & 583.530 & 38.174 & 58.225 & 7.211 \\
Privada & 37.247 & 1.465 & 141.431 & 32.459 \\
\hline Total & $\mathbf{6 2 0 . 7 7 7}$ & $\mathbf{3 9 . 6 3 9}$ & $\mathbf{1 9 9 . 6 5 6}$ & $\mathbf{3 9 . 6 7 0}$ \\
\hline \multicolumn{5}{r}{ Fonte: Elaboração própria com base nos microdados do } \\
\\
Censo da Educação Básica (Brasil/MEC/INEP, 2012a).
\end{tabular}

Os dados nacionais referentes à distribuição das matrículas entre as modalidades de ensino regular e especial (substitutiva), e entre escolas públicas e privadas no Brasil, em 2012, mostram que: 1) dos 820.433 
alunos com necessidades educacionais especiais, 620.777 (75,67\%) estavam na escola regular e, destes, 94\% estavam em escolas públicas; 2) dos 199.656 que estavam na modalidade especial de ensino, 141.431 (70,83\%) estavam em instituições especiais privadas e 58.225 em escolas públicas.

No Paraná, dos 79.309 alunos com necessidades educacionais especiais, $49,98 \%$ estavam na escola regular e $50,02 \%$ estavam em instituições e classes especiais. Observa-se que a proporção de alunos com necessidades educacionais especiais no ensino regular e no ensino especial (substitutivo) é praticamente a mesma, com apenas 31 matrículas a mais no segundo. Condição distinta da nacional em que 24,33\% dos alunos estão matriculados em sistemas segregados de ensino. No que se refere à distribuição entre os sistemas público e privado de ensino, quando matriculados em escolas regulares, $96,17 \%$ dos alunos com necessidades educacionais especiais estão em escolas públicas, de modo semelhante aos números nacionais. Por outro lado, quando matriculados em escolas ou classes especiais, $81,82 \%$ frequentam escolas privadas, prioritariamente filantrópicas, mantendo os números de matrícula um pouco acima dos nacionais.

A comparação destes dados com os apresentados por Brasil (1991a e 1991b) e Meletti e Bueno (2011) nos permite afirmar que, mesmo com uma ampliação do número de alunos com necessidades educacionais especiais na escola regular e pública, há a manutenção de divisão de responsabilidades entre o Estado e a iniciativa privada, no Brasil e, mais ainda, no Paraná.

\section{Condições de Permanência na Escola}

Para a análise das condições de permanência na escola dos alunos com necessidades educacionais especiais, a partir das estatísticas públicas, consideramos três aspectos: a distribuição das matrículas pelas etapas de ensino, o alcance do atendimento educacional especializado e a relação idade série.

No que se refere à distribuição das matrículas por etapa de ensino, consideramos os dados nacionais e paranaenses com o objetivo de dimensionar a realidade do Paraná. Mantemos a análise comparativa entre as modalidades de ensino.

$\mathrm{O}$ alcance do atendimento educacional especializado e a relação idade série foram analisados considerando a situação do estado do Paraná.

O entendimento é o de que o acesso à escola regular deve ser parte de um processo que sustente a permanência de alunos com necessidades educacionais especiais e sua inserção em processos efetivos de escolarização. Para isso, o AEE deve ser ofertado ao maior número de alunos com necessidades educacionais especiais, haja vista sua centralidade na proposição política para a educação especial brasileira.

Educação \& Realidade, Porto Alegre, v. 39, n. 3, p. 789-809, jul./set. 2014

Disponível em: <http://www.ufrgs.br/edu_realidade> 
Indicadores Educacionais sobre a Educação Especial no Brasil e no Paraná

A Tabela 2 apresenta o número de alunos com necessidades educacionais especiais matriculados na Educação Básica, segundo modalidade e etapa de ensino.

Tabela 2 - Número de alunos com NEE, no Brasil e no Paraná, por modalidade e etapa de ensino - 2012

\begin{tabular}{c|c|c|c|c|}
\hline \multirow{2}{*}{ Etapa de Ensino } & \multicolumn{2}{|c|}{ Ensino Regular } & \multicolumn{2}{c|}{ Ensino Especial } \\
\cline { 2 - 5 } & Brasil & Paraná & Brasil & Paraná \\
\hline Creche & 9.662 & 697 & 7.430 & 2.473 \\
Pré-escola & 30.794 & 901 & 11.222 & 2.044 \\
Ensino Fundamental & 485.965 & 31.774 & 124.129 & 18.084 \\
Ensino Médio & 42.499 & 3.700 & 1.090 & 26 \\
EJA & 50.198 & 2.300 & 55.048 & 17.043 \\
\hline
\end{tabular}

Fonte: Elaboração própria com base nos microdados do

Censo da Educação Básica (Brasil/MEC/INEP, 2012a).

Os dados apresentados na Tabela 2 mostram a distribuição das matrículas segundo modalidade e etapa de ensino. Destaca-se a concentração de matrículas no Ensino Fundamental, tanto no Brasil, quanto no Paraná. Dos 820.433 alunos com necessidades educacionais especiais matriculados na Educação Básica Brasileira, 610.094 (74,36\%) estavam no Ensino Fundamental. No Paraná, dos 79.309 alunos com necessidades educacionais especiais, 49.858 (62,86\%) estavam no Ensino Fundamental. Segundo a modalidade de ensino, o ensino especial concentra, em âmbito nacional, $20,34 \%$ dos alunos com necessidades educacionais especiais matriculados no Ensino Fundamental, sendo que este percentual é de 36,27\% no Paraná. Merece destaque o fato de o poder público assumir a maior proporção de matrículas na etapa obrigatória de ensino, mas não pode ser desconsiderado o número de alunos que permanecem em espaços segregados nessa mesma etapa, especialmente no Paraná.

Esta situação não se repete nas etapas de ensino da Educação Infantil, creche e pré-escola. Os registros mostram que pouquíssimas crianças com necessidades educacionais especiais frequentam a creche no Brasil. Dos 17.092 alunos da creche, 56,52\% estão no ensino regular e 43,48\% no ensino especial. No Paraná, dos 3.170 alunos com necessidades educacionais especiais que estão nas creches, 78,01\% frequentam escolas especiais.

Os dados nacionais e paranaenses são bastante distintos no que se refere à pré-escola. Enquanto no Brasil, das 42.016 matrículas, 73,29\% estão na rede regular de ensino, no Paraná ocorre o inverso: 69,40\% estão em escolas especiais. Destaca-se também o baixo número de alunos com necessidade educacional especial que tem acesso a qualquer tipo de escolarização nesta etapa.

O baixo número de matrículas de crianças de 0 a 4 anos na educação infantil pode ser confirmado cotejando os dados do Censo da Edu- 
cação Básica com os demográficos. Segundo o Censo Demográfico de 2010 do IBGE, no Brasil, 385.303 crianças de 0 a 4 anos foram declaradas com pelo menos uma das deficiências investigadas e, destas, 91.916 estavam na categoria não consegue de modo algum; e, no Paraná, tínhamos 15.307 crianças de 0 a 4 anos com pelo menos uma das deficiências investigadas, sendo 4.989 na categoria não consegue de modo algum.

Bueno e Meletti (2011, p. 76) indicam “[...] a pouca relevância que as políticas educacionais voltadas para alunos com deficiência têm dado à educação infantil, expressa pelo número reduzido de matrículas em relação às estimativas de incidência”. O que, segundo os autores, "[...] mostra uma perspectiva política que se volta, basicamente, para o ensino fundamental”.

Com relação ao Ensino Médio, os dados do Censo da Educação Básica revelam que um número muito baixo de alunos com necessidades educacionais especiais tem acesso a essa etapa de ensino. Os dados nacionais indicam que 43.589 alunos com necessidades educacionais especiais estavam matriculados no Ensino Médio em 2012. Destes, $97,49 \%$ estavam no ensino regular. No Paraná, a quase totalidade das matrículas se dá em escolas regulares, sendo que apenas 26 alunos frequentam o Ensino Médio em escolas especiais.

Indicadores educacionais da Educação Básica mostram o afunilamento do número de matrículas gerais entre o Ensino Fundamental e o Ensino Médio brasileiro. Bueno e Meletti (2011) mostram que no Brasil, em 2009, as matrículas gerais no Ensino Médio correspondiam a 25,9\% das do Ensino Fundamental, enquanto as de alunos com necessidades educacionais especiais, matriculados nessa etapa de ensino, correspondiam a 5,6\%. Evidencia-se que o problema de acesso ao Ensino Médio se agrava em se tratando dessa população.

Os dados censitários registram 105.246 matrículas de alunos com necessidades educacionais especiais na Educação de Jovens e Adultos (EJA), no Brasil, em 2012. Destes, 47,69\% estavam no ensino regular e $52,31 \%$ no ensino especial. No Paraná, das 19.343 matrículas, $88,10 \%$ foram efetuadas em espaços segregados de ensino. Destaca-se a concentração de matrículas, principalmente no Paraná, no ciclo de $1^{\mathrm{a}}$ a $4^{\mathrm{a}}$ série.

Meletti e Bueno (2010, p. 11) mostram que as matrículas do alunado da educação especial na EJA parecem “[...] ser a expressão localizada do problema que envolve toda a educação básica no Brasil, qual seja a de que, apesar do incremento das matrículas em geral, os níveis de aprendizagem são muito baixos o que implica retorno à escola por essa modalidade".

A análise das matrículas segundo modalidade e etapa de ensino pode revelar as condições de permanência dos alunos com necessidades educacionais especiais na Educação Básica, por meio dos dados que relacionam a idade do aluno com a série frequentada. A Tabela 3 apresenta os dados da relação idade/série de alunos com idade entre 0 e 18 anos, do ensino de oito anos e do ensino de nove anos no estado do Paraná, em 2012.

Educação \& Realidade, Porto Alegre, v. 39, n. 3, p. 789-809, jul./set. 2014.

Disponível em: <http://www.ufrgs.br/edu_realidade> 
Indicadores Educacionais sobre a Educação Especial no Brasil e no Paraná

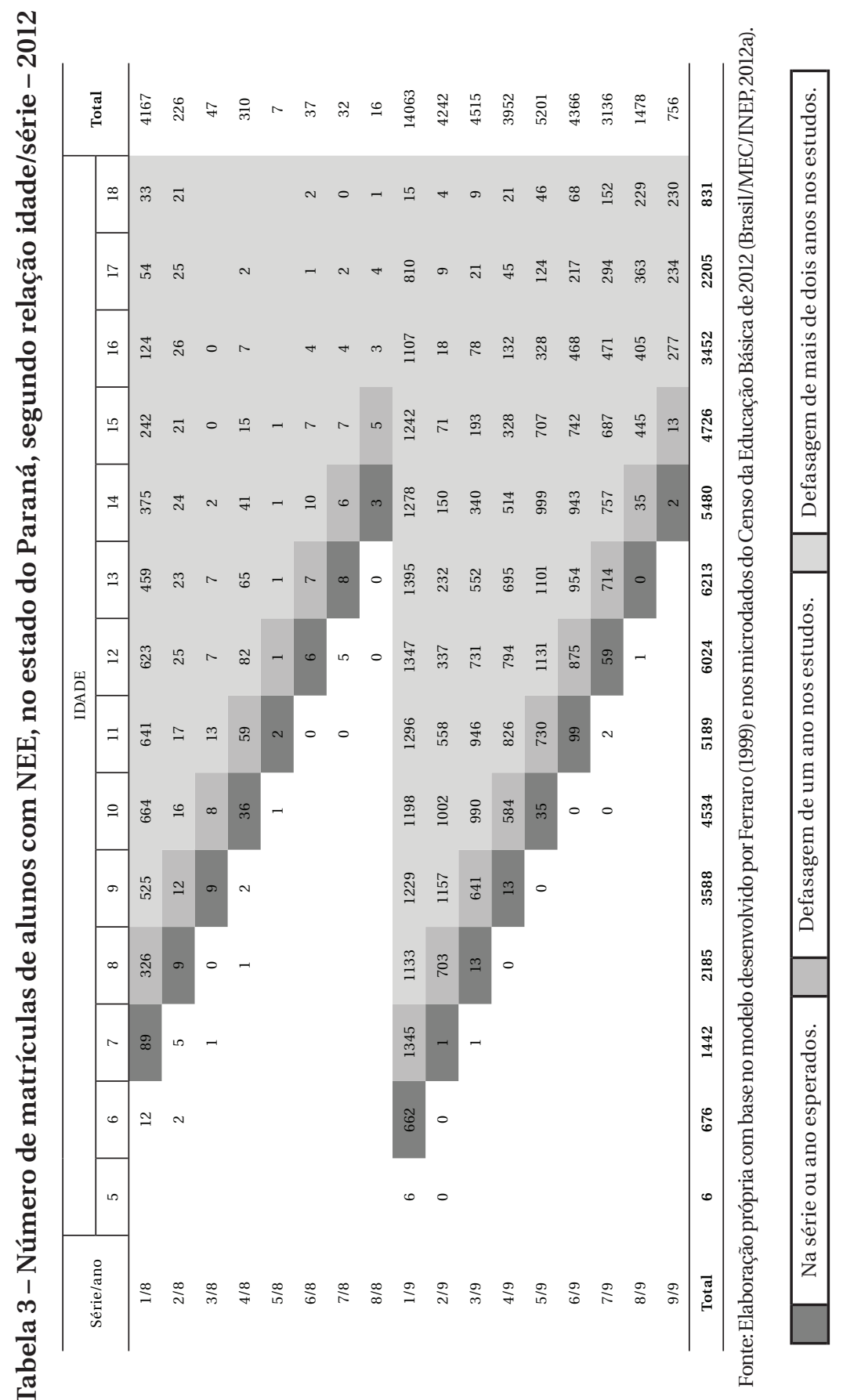


De acordo com os dados da Tabela 4, dos 79.309 alunos com necessidades educacionais especiais no Paraná, 46.551 possuem idade entre 05 e 18 anos. A maior incidência de matrícula ocorre entre 10 e 15 anos, mesma faixa etária que apresenta maior número de alunos em defasagem idade/série, chegando a 07 anos para 1.854 alunos, que se encontram na $1^{\text {a }}$ série de oito anos e no lo ano de nove anos.

No ensino de oito anos, dos 4.842 alunos com necessidades educacionais especiais, apenas 162 (3,34\%) estão em idade adequada à série. No ensino de nove anos, dos 36.508 alunos matriculados, apenas $884(2,42 \%)$ estão no ano adequado.

Os dados indicam que, no ensino de oito anos, 428 (8,83\%) alunos com necessidades educacionais especiais encontram-se em defasagem de um ano e, no ensino de nove anos, $5.640(15,44 \%)$ alunos estão na mesma situação. Isso significa que 34.236 (73,54\%) alunos com necessidades educacionais especiais encontram-se em grande defasagem (2 anos ou mais) em relação à série/ano que deveria frequentar.

Os dados de relação idade/série denunciam a precariedade da permanência e da inserção da população com necessidades educacionais especiais em processos efetivos de escolarização. Ferraro (1999, p. 24) considera que alunos com mais de dois anos de defasagem compõem o grupo dos excluídos na escola, ou seja, “[...] exclusão operada dentro do processo escolar, por meio dos mecanismos de reprovação e repetência”. Este parece ser o caso da maioria do alunado da educação especial paranaense. Tal precariedade corrobora, ainda, as análises tecidas por Ferreira e Ferreira (2004) ao indicarem que os compromissos internacionais assumidos pelo Brasil privilegiam aspectos quantitativos de acesso à escola.

Cumpre questionar a retenção dos alunos com necessidades educacionais especiais nos anos iniciais do ensino fundamental, haja vista a determinação de que, no Paraná, a retenção ocorra apenas a partir da 5a série e do 60 ano (Paraná/SUED/SEED, 2011).

Outro aspecto destacado pela política nacional de Educação Especial, como condição para a inclusão de alunos com necessidades educacionais especiais, é o atendimento educacional especializado (AEE). No entanto, mais uma vez, os dados oficiais mostram a precariedade de um sistema de ensino que se pretende inclusivo. No estado do Paraná, em 2012, haviam 3.814 turmas de AEE, com 21.632 alunos matriculados, o que representa, aproximadamente, 05 alunos por turma. Significa dizer que, dos 79.309 alunos com necessidades educacionais especiais matriculados na Educação Básica paranaense, 27,27\% recebem o atendimento preconizado como o eixo da educação especial brasileira.

Não há registros nos dados oficiais sobre a ocorrência de outro tipo de atendimento especializado que não o AEE, implementado prioritariamente em salas de recursos multifuncionais. Oficialmente, então, a informação é a de que os alunos que não recebem o AEE podem

Educação \& Realidade, Porto Alegre, v. 39, n. 3, p. 789-809, jul./set. 2014.

Disponível em: <http://www.ufrgs.br/edu_realidade> 
Indicadores Educacionais sobre a Educação Especial no Brasil e no Paraná

estar na escola sem nenhum tipo de atendimento direcionado a suas necessidades de apoio. Esse dado, associado aos de defasagem idade série, indica a precariedade do processo de escolarização de alunos com necessidades educacionais especiais, seja em escolas regulares, seja em instituições especiais, assumidas pelo Paraná como escolas da Educação Básica, na modalidade de Educação Especial.

\section{Considerações Finais}

O trabalho teve por objetivo analisar as políticas de escolarização de pessoas com necessidades educacionais especiais por meio dos dados oficiais do poder público sobre o acesso e as condições de permanência dessa população na Educação Básica. Para tanto, analisou os microdados dos Censos da Educação Básica brasileira e do estado do Paraná, segundo modalidade de ensino, etapa de ensino, dependência administrativa da escola e relação idade série de alunos com necessidades educacionais especiais com idade entre 5 e 18 anos.

Apresentamos indicadores educacionais que consideramos fundamentais para a análise da efetividade da implementação das políticas inclusivas no Brasil e que resgatamos aqui para tecer algumas considerações:

1 - Acesso à educação por meio da escola regular.

Mostramos que, se considerarmos a estimativa oficial de incidência de deficiência na população brasileira, a universalização do ensino não atingiu as pessoas com necessidades educacionais especiais, haja vista o baixo número de matrículas destas em relação às matrículas gerais da Educação Básica e ao número de pessoas que são alvo da educação especial.

O aumento das matrículas de alunos com necessidades educacionais especiais na escola regular é indiscutível, mas não pode ser desconsiderada a incidência de matrículas nas escolas e classes especiais. Cumpre destacar a hegemonia da iniciativa privada quando tratamos do atendimento a esta população em espaços segregados de ensino. No Paraná, as matrículas em instituições especiais ainda representam a maioria, especialmente na educação infantil e na EJA, consequência nítida do impacto das políticas educacionais estaduais.

2 - Oferta do AEE como sustentação da permanência de alunos com NEE na escola regular.

Os dados do estado do Paraná evidenciaram o alcance restrito do AEE. Devido à sua centralidade na política para a educação especial brasileira, era de se esperar que um maior número de alunos se beneficiasse desse tipo de serviço, que foi implementado para favorecer a permanência desse alunado na escola regular. Outro aspecto é o AEE ser oficialmente a efetivação da educação especial na escola regular por meio de um trabalho que não se caracteriza como paralelo à educação 
regular. Cumpre questionar que tipo de apoio os alunos com necessidades educacionais especiais, que não recebem AEE, estão tendo na escola regular.

\section{3 - Inserção em processos efetivos de escolarização}

Optamos por analisar o processo de escolarização de alunos com necessidades educacionais especiais, no Paraná, por meio da relação idade série. Os dados revelam uma situação preocupante, que deve ser alvo de outras investigações. A defasagem idade série pode ser consequência tanto da retenção do aluno em uma série, quanto pela entrada tardia na escola. Outro fator, no caso desta população, é a migração dos alunos de classes especiais para salas regulares de ensino sem a devida reclassificação. De todo modo, essas possibilidades, ainda que presentes conjuntamente, não justificam os números de defasagem encontrados.

O problema da defasagem idade série denuncia a precariedade da escolarização da população alvo da educação especial em um sistema de ensino que se pretende inclusivo.

Por fim, o intuito do presente trabalho foi o de, pela análise dos indicadores educacionais oficiais, produzidos no âmbito do próprio Estado, apresentar um conjunto de reflexões deles advindas, que possam contribuir tanto para a avaliação dessas políticas, quanto para a análise do acesso, da permanência e da escolarização de alunos com necessidades educacionais especiais na Educação Básica.

Recebido em 13 de março de 2014 Aprovado em 29 de maio de 2014

\section{Referências}

APOIO do Paraná para escolas de Apaes vira lei pioneira no País. Agência de Notícias do Paraná, 15 ago. 2013. Disponível em: <http://www.aen.pr.gov.br/ modules/noticias/article.php?storyid=76101>. Acesso em: 01 out. 2013.

BRASIL. Constituição da República Federativa do Brasil, 1988.

BRASIL. Ministério da Educação. Coordenação de Informações para o Planejamento. Sinopse estatística da Educação Especial. V. I. 1988. Brasília: MEC/CIP, 1991a.

BRASIL. Ministério da Educação. Coordenação de Informações para o Planejamento. Sinopse estatística da Educação Especial. V. II. 1988. Brasília: MEC/ CIP, 1991b.

BRASIL. Lei n. 9.394, de 20 de dezembro de 1996. Estabelece as diretrizes e bases da educação nacional. Diário Oficial [da República Federativa do Brasil], Brasília, DF, v. 134, n. 248, 23 dez. 1996.

BRASIL. CNE. Resolução CNE/CEB n. 1, de 11 de setembro de 2001, que institui as Diretrizes Nacionais para a Educação Especial na Educação Básica. Brasília, 2001.

BRASIL. Ministério da Educação. Instituto Nacional de Estudos e Pesquisas Educacionais Anísio Teixeira - INEP. Censo Escolar da Educação Básica -2004.

Educação \& Realidade, Porto Alegre, v. 39, n. 3, p. 789-809, jul./set. 2014. 
Indicadores Educacionais sobre a Educação Especial no Brasil e no Paraná

Disponível em: <http://www.inep.gov.br/basica/levantamentos/microdados. asp>. Acesso em: 21 dez. 2010.

BRASIL. Ministério da Educação. Instituto Nacional de Estudos e Pesquisas Educacionais Anísio Teixeira - INEP. Censo Escolar da Educação Básica - 2005. Disponível em: <http://www.inep.gov.br/basica/levantamentos/microdados. asp>. Acesso em: 21 dez. 2010.

BRASIL. Ministério da Educação. Instituto Nacional de Estudos e Pesquisas Educacionais Anísio Teixeira - INEP. Censo Escolar da Educação Básica -2006. Disponível em: <http://www.inep.gov.br/basica/levantamentos/microdados. asp>. Acesso em: 21 dez. 2010.

BRASIL. Ministério da Educação. Instituto Nacional de Estudos e Pesquisas Educacionais Anísio Teixeira - INEP. Censo Escolar da Educação Básica - 2007. Disponível em: <http://www.inep.gov.br/basica/levantamentos/microdados. asp>. Acesso em: $21 \mathrm{dez} .2010$.

BRASIL. Ministério da Educação. Instituto Nacional de Estudos e Pesquisas Educacionais Anísio Teixeira - INEP. Censo Escolar da Educação Básica 2008a. Disponível em: <http://www.inep.gov.br/basica/levantamentos/microdados.asp>. Acesso em: 21 dez. 2010.

BRASIL. Ministério da Educação. Secretaria de Educação Especial. Política nacional de educação especial na perspectiva da educação inclusiva. Brasília: MEC/SEESP, 2008b.

BRASIL. Conselho Nacional de Educação. Câmara de Educação Básica. Resolução n. 4, de 02 de outubro de 2009. Diretrizes Operacionais para o Atendimento Educacional Especializado na Educação Básica, modalidade Educação Especial. Brasília, 2009a.

BRASIL. Ministério da Educação. Instituto Nacional de Estudos e Pesquisas Educacionais Anísio Teixeira - INEP. Censo Escolar da Educação Básica 2009b. Disponível em: <http://www.inep.gov.br/basica/levantamentos/microdados.asp>. Acesso em: $21 \mathrm{dez} .2010$.

BRASIL. Instituto Brasileiro de Geografia e Estatística (IBGE). Banco de Dados Agregados do Censo Demográfico 2010. 2010a. Disponível em: <http://www.sidra.ibge.gov.br>. Acesso em: 01 out. 2013.

BRASIL. Ministério da Educação. Instituto Nacional de Estudos e Pesquisas Educacionais Anísio Teixeira - INEP. Censo Escolar da Educação Básica - 2010b. Disponível em: <http://www.inep.gov.br/basica/levantamentos/microdados. asp >. Acesso em: 21 dez. 2010.

BRASIL. Decreto 7.611 de 17 de novembro de 2011. Dispõe sobre a educação especial, o atendimento educacional especializado e dá outras providências. Brasília: 201la. Disponível em: <http://www.planalto.gov.br/ccivil_03/_Ato20112014/2011/Decreto/D7611.htm>. Acesso em: $01 \mathrm{dez} .2011$.

BRASIL. Instituto Nacional de Estudos e Pesquisas Educacionais Anísio Teixeira (INEP). Censo Escolar. Brasília, DF: MEC/INEP, 2011b. Disponível em: <http:// portal.inep.gov.br/basica-censo>. Acesso em: 01 out. 2013.

BRASIL. Ministério da Educação. Instituto Nacional de Estudos e Pesquisas Educacionais Anísio Teixeira - INEP. Censo Escolar da Educação Básica -2012a. Disponível em: <http://www.inep.gov.br/basica/levantamentos/microdados. asp >. Acesso em: 01 out. 2013.

BRASIL. Instituto Brasileiro de Geografia e Estatística (IBGE). Censo Demográfico 2010: características gerais da população. Rio de Janeiro: IBGE, 2012b. 
CONFERÊNCIA MUNDIAL SOBRE NECESSIDADES EDUCACIONAIS ESPECIAIS. Declaração de Salamanca e linha de ação sobre necessidades educativas especiais, 1994 Brasília. Anais... Brasília: CORDE, 1994.

FERRARO, Alceu Ravanello. Diagnóstico da Escolarização no Brasil. Revista Brasileira de Educação, Rio de Janeiro, ANPED, n. 12, p. 22-47, set./dez. 1999.

FERREIRA, Maria Cecília Carareto Ferreira; FERREIRA, Julio Romero. Sobre Inclusão, Políticas Públicas e Práticas Pedagógicas. In: GÓES, Maria Cecília Rafael; LAPLANE, Adriana Lia F. Políticas e Práticas de Educação Inclusiva. 2 ed. Campinas: Autores Associados, 2004. P. 21-48.

GARCIA, Rosalba Maria Cardoso. Política de Educação Especial na Perspectiva Inclusiva e a Formação Docente no Brasil. Revista Brasileira de Educação, Rio de Janeiro, ANPED, v. 18, n. 52, p. 101-239, jan./mar. 2013.

JANNUZZI, Gilberta Sampaio de Martino. A Luta pela Educação do Deficiente Mental no Brasil. São Paulo: Cortez: Autores Associados, 1997.

KASSAR, Mônica de Carvalho Magalhães; MELETTI, Silvia Márcia Ferreira. Análises de Possíveis Impactos do Programa Educação Inclusiva: Direito à Diversidade. Ciências Humanas e Sociais em Revista, Rio de Janeiro, EDUR, v. 34, n. 12, p. 49-63, jan./jun. 2012.

MELETTI, Silvia Márcia Ferreira; BUENO, José Geraldo Silveira Bueno. Os Indicadores Educacionais como Meio de Avaliação das Políticas de Educação Especial no Brasil - 2000/2009. In: BUENO, José Geraldo Silveira. Educação Especial Brasileira: 20 anos depois. São Paulo, EDUC, 2011. P. 159-182.

MELETTI, Silvia Márcia Ferreira; BUENO, José Geraldo Silveira Bueno. Escolarização de Alunos com Deficiência: uma análise dos indicadores sociais no Brasil (1997-2006). In: 33 REUNIÃO ANUAL DA ANPED, 2010, Caxambu. Anais... Caxambu: 2010. 1 CD-ROM. P. 1-17.

PARANÁ. SUED/SEED. Resolução 3.600/2011. Autoriza a alteração na denominação das Escolas de Educação Especial para Escolas de Educação Básica, na modalidade de Educação Especial. 2011.

PARANÁ. Lei 17.656, que institui o Programa Estadual Permanente às Entidades Mantenedoras de Escolas que ofertam Educação Básica na Modalidade Educação Especial, denominado Todos Iguais pela Educação. 2013.

SAVIANI, Dermeval. Sistema Nacional de Educação articulado ao Plano Nacional de Educação. Revista Brasileira de Educação, Rio de Janeiro, ANPED, v. 15, n. 44, p. 380-412, maio/ago. 2010.

Silvia Márcia Ferreira Meletti é professora Associada do Departamento de Educação e coordena o Programa de Pós-Graduação em Educação da Universidade Estadual de Londrina. Possui mestrado em Educação Especial (Educação do Indivíduo Especial) pela Universidade Federal de São Carlos (1997), doutorado em Psicologia Escolar e do Desenvolvimento Humano pela Universidade de São Paulo (2006) e pós-doutorado pela Pontifícia Universidade Católica de São Paulo.

E-mail:smeletti@gmail.com 